\title{
Introducción al dualismo maniqueo ${ }^{1}$
}

\author{
Introduction to the Manichaeism dualism
}

Molina Javier

jmolina.joh@gmail.com

Universidad de Valparaíso.

\section{Resumen:}

En el presente artículo revisamos el dualismo maniqueo, como punto de clivaje para adentrarnos en su propuesta escatológica. De este modo, esclarecemos el origen del maniqueísmo como sistema religioso y exhibimos la lucha entre Luz y Tinieblas, donde la victoria de la Luz sería la única escatología posible. En definitiva, reconocemos al dualismo maniqueo como propuesta éticopolítica para la configuración de una forma de vida específica.

Palabras claves: Luz, Tinieblas, escatología, dualismo maniqueo.

\begin{abstract}
In this article we check the Manichaeism dualism, it's like a cleavage point to enter his eschatological approach. Thereby, we clear up the genesis of the Manichaeism like religious system and we exhibit the struggle between Light and Darkness, where, the Light's victory would be the only possible eschatology. Ultimately, we recognize the Manichaeism dualism like an ethicpolitical proposition to make up a specific form of life.
\end{abstract}

Keywords: Light, Darkness, eschatology and Manichaeism dualism.

“(...) estos dos árboles, y separa el uno del otro, y sabe que no llegaron a existir el uno a partir del otro, que no precedieron el uno del otro: no proceden de uno."2

Kephalaion 2

En primera instancia, cabe destacar el ambiente que se vivía en el siglo IV e. c. ${ }^{3}$, ya que la decadencia del Imperio romano permitiría que varios movimientos religiosos tomen fuerza, como

\footnotetext{
${ }^{1}$ Cabe destacar que una primera versión de este artículo forma parte de mi tesis de magíster en Filosofía: el Reino de Dios agustiniano como forma-de-vida. A partir de ella, estoy desarrollando profundizaciones en algunas problemáticas para su próxima publicación en formato libro.

${ }^{2}$ Existen sólo algunos fragmentos traducibles de estos textos, para profundizar, recomiendo revisar a Bermejo y Montserrat (2008: 142-143).
} 
también un importante debate entre las distintas posiciones. En ese marco, Agustín escribía La Ciudad de Dios; ya que varios historiadores habrían buscado culpar al cristianismo de la debacle ${ }^{4}$. De hecho, la conquista de Roma por los visigodos encabezados por Alarico durante agosto del 410 e. c., habría sido un punto clave como telón de fondo no sólo de la vida agustiniana, sino un momento histórico donde hay múltiples discursos y formas de vivir disputando para asentarse como la mejor opción para enfrentar los tiempos catastróficos (Marrou, 1960).

En este sentido, tras su conversión, Aurelius Augustinus vivirá humildemente (Chapsal, 2018) como seguidor de Cristo, constituyéndose en ejemplo de la moral cristiana, aún bajo aquel difícil contexto donde grandes fuerzas sociales veían al cristianismo como directo culpable de la decadencia del Imperio. De hecho, a pesar de la conversión de Constantino, el paganismo mantenía una gran credibilidad colectiva. Incluso, se comenzó a blasfemar contra el cristianismo, contra el Dios verdadero, "lo que hería profundamente a San Agustín era que se achacase al Salvador la perdición y ruina del mundo" (Capanaga, 1977: 9). Hasta los mismos cristianos tenían ciertas dudas y el desconcierto era generalizado en el ambiente de la época. Así, la contienda era inminente:

"La polémica con el paganismo estaba en plena calle y era necesario guarnecer a los fieles con las armas de la sabiduría cristiana para que se mantuviesen en la fe. Durante el año 411 no descansó en esta tarea. Se hizo un defensor incansable de la ciudad de Dios, atacada injustamente por los militantes paganos." (Capanaga, 1977: 13)

En gran medida, como dejan entrever los títulos del Libro I: En defensa de la religión cristiana, y del Libro II: Los dioses y la degradación de Roma, los objetivos son evidentes: Agustín busca separar al cristianismo de la caída del Imperio, exhibiendo, en la primera parte ${ }^{5}$ de esta obra, los vínculos entre la decadencia del Imperio y los dioses paganos, e intentando la salvación como sistema de creencias para impulsar su propuesta escatológica (Agustín, 2005; Dal Maschio, 2015). En definitiva, tras la decadencia romana una apologética del cristianismo aparecía como tarea urgente. Y, en este mismo sentido, reposicionar la escatología cristiana, con su noción del Reino de Dios como posibilidad vital, enfrentándose a los demás movimientos religiosos con relevancia en dicho período, donde el maniqueísmo ocupaba un relevante lugar (Bermejo, 2008; Viale, 2012).

Asimismo, para comprender la conversión agustiniana es inexorable reconocer al maniqueísmo; recordemos que Agustín fue oyente casi una década. Inclusive, cuando se le ordena « toma y lee»,

\footnotetext{
${ }^{3}$ La abreviatura e.c. hace referencia a la era común, lo que nos parece más propicio para hablar sobre esta religión (Bermejo, 2008).

${ }^{4}$ Existe, evidentemente, una profunda discusión historiográfica respecto a las causas de la caída del Imperio Romano que, dado los objetivos planteados aquí, no profundizaremos. Entre otros, se puede revisar la obra de Peter Brown (2016) Por el ojo de la aguja. Trad. Agustina Luengo. Barcelona: Ed. Acantilado.

${ }^{5}$ Aun cuando no es parte central de nuestra tesis, evidentemente, es importante tener en cuenta los Libros I-X para comprender el posicionamiento de los Libros posteriores. Como también para comprender contra quiénes, o mejor dicho, qué creencias, estaba luchando Agustín.
} 
se toparía con un fragmento bíblico ${ }^{6}$ que podría asemejarse a ciertas enseñanzas maniqueas que, precisamente, estaría dejando atrás. En gran parte, debido a que muestra un rechazo hacia lo carnal, vestirse del Señor Jesucristo, desechar las preocupaciones carnales, un tanto similar a las prácticas ascéticas que proponía también el maniqueísmo (Bermejo, 2008), y enfocarse más sobre el mundo interior (Stoddart, 2002: 37-48) ${ }^{7}$, lo cual, efectivamente, se distancia de la vida errante propuesta por Mani.

De hecho, consideramos que Agustín -particularmente, con su obra La Ciudad de Dios- vendría a cerrar la discusión soteriológica de una época, aun cuando se encuentren comunidades maniqueas en el siglo XIII, inclusive. Ahora bien, las refutaciones agustinianas, y de otros cristianos, contra el maniqueísmo, posibilitaron las persecuciones y acusaciones papales (Villegas, 2004; Rojas, 2016; Escribano, 1990; Claro, 2009), que ayudarán a la desaparición de esta religión. De esta manera, la importancia de revisar el dualismo maniqueo tiene consecuencias tanto en las conceptualizaciones que del cristianismo-agustiniano como también por la construcción de un discurso antimaniqueísta que permitirá las refutaciones teológico-políticas a esta religión. En consecuencia, retomamos breves fragmentos de Agustín, como uno de los principales apologistas cristianos frente al maniqueísmo, para exponer estos aspectos.

Ahora, revisamos la posición maniquea sobre el mal, exponiendo su visión dualista del ser, debido a que tendría fuertes implicancias en la antropología agustiniana e, inclusive, en la configuración de un dualismo antropológico de toda la cristiandad (Dussel, 1974), como también en la gama cenobítica del cristianismo posterior al siglo IV (Villegas, 2004). Por lo mismo, exhibimos ciertos fragmentos agustinianos, para enfocarnos en el problema sobre el mal o, mejor dicho, del origen del mal en el maniqueísmo.

Como decíamos, Agustín fue oyente maniqueo durante casi una década. En términos estrictos fue auditor, es decir, una de las dos categorías que existen en el maniqueísmo para la división de sus fieles. Cabe destacar que ésta es la que complementa a los electi y las electae (podían ser tanto hombres como mujeres ${ }^{8}$ ), que conformarían la élite de la Iglesia maniquea y, en consecuencia, mantienen un rigor comportamental más hondo que los auditores. Estos últimos, también denominados ayudantes, mantendrían aún contacto con la mundanidad, permitiendo que aquéllos y aquéllas puedan dedicarse plenamente a la religión. En definitiva, éstos trabajan y mantienen, mientras que los electi y las electae son la mediación entre auditores y Dios (Bermejo, 2008). Creemos que, precisamente, su pasado maniqueo, le permitirá a Agustín confrontar la doctrina

\footnotetext{
6 "Como de día andemos decentemente, no en diversiones estrepitosas y borracheras, no en coito ilícito y conducta relajada, no en contienda y celos. Antes bien, vístanse del Señor Jesucristo, y no estén haciendo planes con anticipación para los deseos de la carne." Romanos 13, 13-14. Destacado nuestro.

${ }^{7}$ En gran medida, como señalaba Stoddart (2002) respecto al cristianismo como una religión no-pública, sino más bien silenciosa e interiorista - por llamarlo de algún modo. De esta forma, lo diferencia del Islam que tiene un culto y ciertas prácticas públicas que lo distinguen.

${ }^{8}$ Sin embargo, únicamente los electi habrían podido ocupar los puestos, jerárquicamente, más importante dentro de la Iglesia maniquea.
} 
dualista de aquéllos y ganar debates públicos, además de una prolífica obra antimaniquea que nos deja el obispo de Hipona.

En primera instancia, cabe destacar que el maniqueísmo ha sido entendido como una religión, aun cuando algunos insistan con denominarla como una secta (Brown, 1969). Ha sido formada a partir del profeta Mani, nacido aproximadamente en el 216 e. c. en Mesopotamia, que se encontraba bajo dominio parto. Cabe señalar que múltiples veces ha sido traducido como Manes, debido a su escritura griega: Mánēs, y sería quien viene a culminar una línea profética de Jesús, Buda y Zoroastro, siendo continuador de ciertas enseñanzas de religiones precedentes. Se destaca que a los cuatro años ingresa en la secta bautista de los elcasaítas, con quienes recién rompe tras veinte años para comenzar la conformación del maniqueísmo. Por último, cabe decir que Mani es encarcelado en 276 e. c., dado el enfrentamiento religioso existente y la previa muerte de su protector en los poderes políticos del Imperio: Šābuhr I. Es ahí donde el profeta muere, aparentemente, al año siguiente. A pesar de que las razones de su encarcelamiento no están del todo claras, incluso, se desconoce el destino del cadáver, el maniqueísmo utilizó dicho acontecimiento como cierto paralelismo a la crucifixión de Jesús (Bermejo, 2008).

En este sentido, ha sido una enorme controversia intentar clarificar las influencias del maniqueísmo, lo que ha llevado a caracterizarlo de múltiples maneras dentro de la historia de las religiones, ya sea "(...) como una herejía cristiana, como un intento de reforma del zoroastrismo, como una religión con raíces budistas o como una forma de recreación de una antigua religión mesopotámica o babilónica (...)" (Viale, 2012: 147-148). Por su parte, Puech señala que “(...) es una gnosis, nacida en parte de los gnosticismos que los heresiólogos se ocuparon de clasificar" (Puech, 1982), aunque tampoco sería reducible a una gnosis, ya que aun manteniendo elementos comunes, tiene una pretensión universalista que la diferencia de aquélla. En definitiva, el maniqueísmo tomaría elementos de creencias previas y aledañas, para configurar una religión con importante sincretismo, aunque no reducible a él (Bermejo, 2008: 77). En gran parte, su originalidad y distinción podemos encontrarla en la doctrina de los dos principios: Luz y Tiniebla, y sus tres tiempos: separación originaria, mezcla y separación futura. En otras palabras,

“(...) el Bien no tiene absolutamente nada que ver con el Mal, en cuya existencia no es cómplice. El Mal es un dato bruto en cuya realidad la Luz -bondad absoluta y sin resquicios- carece de toda participación. La comprensión cabal del postulado de la existencia de dos principios se considera prerrequisito indispensable para la progresión en el conocimiento y la obtención de la salvación.” (Bermejo, 2008: 81)

Entonces, Mani con una fuerte autoconciencia histórica de su posicionamiento, como último enviado de Dios, supo construir un movimiento de gran envergadura. De hecho el maniqueísmo postula que, “(...) si bien Mani es el último y definitivo revelador, la humanidad ha recibido anteriormente toda una serie de emisarios enviados por la divinidad." (Bermejo, 2008: 131) Aun cuando tampoco sea una idea únicamente maniquea, sino que también provendría de los bautistas elcasaítas. En breve, más que conseguir una clara disección entre cuáles son elementos propiamente 
maniqueos y cuáles tienen -más o menos- matices, conviene constatar la importante mezcla de los sistemas soteriológicos de la época.

Su permanencia en la comunidad bautista elcasaíta durante dos décadas debió ejercer un relevante influjo en la configuración de su cosmovisión. Incluso, debió haber conocido la Torá, y el rol de Jesús en el maniqueísmo expone su conocimiento profundo de los textos neotestamentarios, especialmente, de las cartas paulinas; en particular, a las epístolas a los Gálatas y Corintios (Bermejo, 2008: 45). De hecho, el distanciamiento de la comunidad elcaísta, donde Mani estuvo cerca de veinte años, habría sido paulatino:

"Según algunos testimonios, la primera experiencia decisiva de Mani habría sucedido a la edad de doce años $\left(c a .^{9} 228\right)$, y en ella el mensajero celeste le habría informado acerca de su naturaleza trascendente y ordenado apartarse de los valores de la comunidad bautista, aunque sólo interiormente. La segunda habría tenido lugar a la edad de veinticuatro años ( $c a$. 240), y en ella Mani habría recibido la orden de abandonar la comunidad, manifestarse públicamente y predicar a la humanidad un nuevo mensaje." (Bermejo, 2008: 48)

En este sentido, heredó varios componentes judeocristianos como elementos de profetología, cristología, apocalipticismo y encratismo (Bermejo, 2008: 44). En gran medida, cabe destacar que viniendo de una "(...) tradición monoteísta judeocristiana y particularista (...)" (Bermejo, 2008: 48) constituye una vocación universalista con un fuerte dualismo, por lo que se constata que el maniqueísmo no es meramente un sincretismo -como ya habíamos destacado- sino una composición religiosa novedosa que tiene ciertas continuidades, como también rupturas.

Los maniqueos utilizaron múltiples métodos para difundir el mensaje, e inclusive crearon una prolífera escritura para propagar el mensaje sin limitaciones geográficas ni linguiísticas (Bermejo, 2008: 137). Asimismo, produjeron obras pictóricas (Gulácsi, 2016: 435-455) -dado el inmenso analfabetismo del período- $y$, junto con los viajes misioneros por distintas regiones, ocasionaron una fuerte expansión del maniqueísmo entre Europa hasta China, superando las limitaciones geográficas que habían tenido los reveladores precedentes (Zoroastro en Persia, Jesús en Palestina y Buda en India) dada la impronta universalista del movimiento. Así, la impronta misionera de Mani y sus discípulos nos permite comprender que todavía en el siglo VIII existía un estado maniqueo en las fronteras del Imperio chino y en el siglo XIII todavía quedaban maniqueos "(...) en FuKién, y algunos de los documentos maniqueos más reveladores hasta ahora descubiertos están escritos en chino" (Brown, 1969: 53), esclareciendo el universalismo de esta religión.

De manera similar, la reconstrucción de los textos maniqueos (Bermejo y Montserrat, 2008) ${ }^{10}$ a cargo de Fernando Bermejo Rubio y José Montserrat Torrents, destaca la multiplicidad idiomática de la misión, como también se exhibe la importancia de los escribas en el movimiento (Bermejo,

\footnotetext{
${ }^{9}$ La abreviatura ca. quiere decir cercanamente a (Bermejo, 2008).

${ }^{10}$ En el equipo de investigación destacan: Xavier Ballestín, Nathalie Bosson, Alberto Cantera, Francisco del Río, Jean-Daniel Dubois, Antonio Prevosti, Alberto Quevedo, Madeleine Scopello, Xavier Tremblay, además de Bermejo y Montserrat que estuvieron a cargo de la edición.
} 
2008: 152). En este sentido, encontraremos textos provenientes de fuentes iraníes, coptas, chinas, latinas y griegas, exponiendo también los diversos puntos de influencia -y confluencia- de esta pequeña secta de reputación siniestra (Brown, 1969). De este modo, en el maniqueísmo se pueden destacar influencias, al menos, de Persia (Zoroastro), Asia Central (Buda) y el mundo romano (Cristo). Incluso, para algunos sería una religión sincretista que llevaría la doctrina cristiana a su madurez (Rojas, 2016: 98), aunque "las influencias recibidas no se limitan, empero, al ámbito de los variados cristianismos de la época.” (Bermejo, 2008: 46)

A pesar de la identificación con los profetas de otras religiones, “(...) los paganos los miraban con horror y los cristianos ortodoxos con temor y odio" (Brown, 1969: 56), muchos lo denominaron un grupo extremista de reputación siniestra (Brown, 1969: 56). De este modo, el maniqueísmo se configuró como “(...) espejo de todos los males (...) [y] el más negativo correspondía a sus inclinaciones por las prácticas maléficas" (Escribano, 1990: 37), entre las que se encontraba la ingestión de semen humano por parte de los electi (Villegas, 2004: 222).

"La comunidad elcasaíta unía la salvación a la idea de pureza, pero sus miembros parecen haber aspirado a la obtención de ésta mediante la práctica de frecuentes abluciones e inmersiones. Mani parece haber considerado que ese modo de obtener la pureza era inútil y estaba condenado indefectiblemente al fracaso: desde su punto de vista, el cuerpo es intrínsecamente malo, por lo que las abluciones repetidas no conducen a nada.” (Bermejo, 2008: 51)

De este modo, se exhibe la conceptualización negativa del cuerpo en el maniqueísmo. Por ello, los maniqueos prefirieron la prohibición de la ingesta de carne, prolongados ayunos y el rechazo a la procreación humana, como forma de rechazar la corporalidad. Estos últimos preceptos, configuran algunas claves de los mandamientos de electi y electae, y, además, toman notable sentido en la negación de la corporalidad como vía de redención maniquea. De esta manera, los misioneros maniqueos, practicantes de un importante ascetismo y tabúes alimentarios (Villegas, 2004: 229), crearon un estilo de vida singular, lo que implicó que se les reconocieran como austeros e, incluso, de cierta palidez de cara (Brown, 1969: 61). En síntesis, una forma de usar el cuerpo que implica importantes restricciones, las que estarían fundadas en el rechazo al Reino de las tinieblas, en este caso, lo carnal.

Como hemos señalado, el maniqueísmo rechazó al cuerpo, entendiéndolo como una manifestación de las Tinieblas. Por ello, se produjo una forma de vivir particular. Así, y recordando que la religión se territorializaba, traduciendo sus obras a distintos idiomas, e incorporando elementos locales, mantuvieron un tronco común que sería respetado tanto por misioneros y misioneras como por las comunidades asentadas de oyentes. De este modo, varias reglas fueron, de manera generalizada, en todas sus vertientes, como vemos en la siguiente tabla produjeron la religión maniquea:

\begin{tabular}{|l|l|l|l|}
\hline \multicolumn{4}{|c|}{ Cinco mandamientos de los electi y las electae (DeBuhn, 2000; Bermejo, 2008) } \\
\hline Fuentes & Fuentes coptas & Fuentes iranias & Fuentes turcas \\
\hline
\end{tabular}




\begin{tabular}{|l|l|l|l|}
\hline árabes & & & \\
\hline No mentir & No mentir & Veraz & No pecar \\
\hline No injuriar & No matar & No injuriar & No cometer acciones sucias y/o malas \\
\hline No casarse & Pureza & Conducta religiosa & Pureza de cuerpo \\
\hline $\begin{array}{l}\text { No comer } \\
\text { carne ni beber } \\
\text { vino }\end{array}$ & No comer carne & Pureza de boca & Pureza de boca \\
\hline No codiciar & Voto de pobreza & Voto de pobreza & Voto de pobreza \\
\hline
\end{tabular}

Por otro lado, para algunos autores, más que una consecuencia de las pretensiones universalistas del movimiento, “(...) que la religión maniquea se extendiera por el mundo cristiano romano [sería más bien] un síntoma notable del «torbellino» religioso de la época” (Brown, 1969: 52), siendo aún más sorprendente su expansión hacia Oriente. Además, las luchas soteriológicas que se vivían en el período, habrían implicado que Mani concibiera “(...) la realidad como un conflicto de dos reinos ineluctablemente enfrentados[, debido a que] vivió en un mundo convulso en el que la rivalidad y el choque de ejércitos parece haber sido constante." (Bermejo, 2008: 38)

En este sentido, la producción de una ontología cristiana, y producir un marco epistémico-político que le sustente, supone el sometimiento de otros saberes, “(...) los cuales son descalificados como demoníacos o como incompetentes: ingenuos, jerárquicamente inferiores (...) [y] la tradición se encarga también de ocultar su trabajo sucio, la violencia que genera su sistema de exclusiones (...)" (Claro, 2009: 17). Así, lo que Andrés Claro reflexiona a partir del sometimiento y exclusión de los saberes hebreos, específicamente, cabalísticos, por la tradición cristiana, nos serviría para comprender también la denigración que recibieron los seguidores de Mani-como exponíamos recientemente.

En esa línea, Peter Brown llega a denominar a los maniqueos como bolcheviques del siglo IV ${ }^{11}$ (Brown, 1969: 56), exponiendo que los maniqueos creían ser portadores de una solución radical y de origen extranjero, buscando infiltrarse en la Iglesia cristiana (Brown, 1969). No obstante, es interesante recordar que, en su momento, también los cristianos fueron una secta perseguida por las instituciones oficiales. Así, lo expone Celso ${ }^{12}$ en El Discurso verdadero contra los cristianos, texto del siglo II d. C.:

"Hay una raza nueva de hombres nacidos ayer, sin patria ni tradiciones, asociados entre sí contra todas las instituciones religiosas y civiles, perseguidos por la justicia, universalmente cubiertos de infamia, pero autoglorificándose con la común excreción: son los Cristianos. Mientras las sociedades autorizadas

\footnotetext{
${ }^{11}$ Dejando en evidencia una clara tendencia política del autor, pero más importante aún su tono peyorativo de exponer las doctrinas maniqueas, siendo un ferviente defensor de las posturas antimaniqueas cristianas.

${ }^{12}$ Esta problemática la profundizamos en un artículo que estamos trabajando sobre algunas persecuciones religiosas del período.
} 
y organizaciones tradicionales se reúnen abiertamente y a la luz del día, ellos mantienen reuniones secretas e ilícitas para enseñar y practicar sus doctrinas. Se unen entre sí por un compromiso más sagrado que un juramento y así quedan confabulados para conspirar con más seguridad contra las leyes y así resistir más fácilmente a los peligros y a los suplicios que les amenazan.” (Celso, 1989: 19)

Retomamos con interés este fragmento, ya que se asimila bastante a la trama discursiva que presentan las posiciones agustinianas contra los maniqueos. Posteriormente, en gran parte por estas mismas afirmaciones -entre otras razones-, se producirá una cruel e importante persecución por la Iglesia cristiana a estos grupos. Del mismo modo en que san Agustín se refería a la situación de los judíos, señalando que "(...) deben vagar y ser fugitivos sobre la tierra, vivir en el exilio perpetuo" (Claro, 2007: 100), esclareciendo la actitud del cristianismo frente a dicho pueblo. En otros términos, lo que se decía de los cristianos, serán las mismas maquinarias reapropiadas por éstos, para someter a los otros, ya sean maniqueos, judíos o paganos. Para cerrar, las palabras del ya convertido obispo de Hipona sobre el delirio maniqueo, aun cuando haya formado parte de dicha soberbia y carnalidad:

"de esta manera, vine a caer entre unos hombre delirantes de soberbia, carnales y locuaces en exceso, en cuya boca había insidias del diablo y un lazo viscoso tejido con las sílabas de tu nombre, el del Señor Jesucristo y el del Paráclito, consuelo nuestro, el Espíritu Santo. Estos nombres no se apartaban de sus bocas, si bien sólo en cuanto al sonido y al ruido de la lengua; por lo demás, en su corazón estaba ausente de la verdad. Decían 'Verdad, verdad' y mucho me hablaban de la verdad, pero nunca estaba en ellos; al contrario, enunciaban cosas falsas no sólo de ti, que verdaderamente eres la verdad, sino también de estos elementos del mundo, creación tuya. Sobre estos elementos dicen cosas verdaderas aun los filósofos a quienes debi dejar atrás por tu amor, Padre mío sumamente bueno, belleza de todas las cosas hermosas." (Agustín, 2005: 85-86)

A pesar que formar parte de estas congregaciones habría permitido a "(...) Agustín el ser un joven «espiritual» y muy austero." (Brown, 1969: 60) Sin embargo, aun cuando haya gustado de dicha elevación, habría ciertos preceptos maniqueos que distancian las búsquedas agustinianas y lo llevarán, por el contrario, a acercarse al cristianismo. Esto último, podríamos encontrarlo más que en la ética maniquea, y en su respectiva forma de vida con las reglas expuestas -en la tabla- que podrían no distanciarse tanto de las Reglas agustinianas, en la impronta dualista del maniqueísmo. Por ello, a continuación profundizamos en la distinción entre el Reino de la Luz y el Reino de las Tinieblas para comprender de mejor manera la escatología maniquea.

Bajo estos parámetros, se decía que los maniqueos se debían al culto del sol y de la luna (Villegas, 2004), y aun cuando el culto astral también estaba ampliamente difundido en las clases populares romanas, fue contra aquéllos que focalizaron sus críticas. En todo caso, dicha afirmación no sería correcta, sino que más bien los maniqueos utilizaban al sol y la luna como mediadores del Alma Viviente, ya que cumplían una función como “(...) qibla o punto de orientación para la oración, en 
la medida en que eran considerados vehículos de la liberación usados por las potencias divinas para hacer ascender las partículas luminosas." (Bermejo, 2008: 159) En suma, no existiría tal culto del sol y la luna, sino su uso como mediadores de su práctica cultual.

Ahora bien, en las comunidades los oyentes maniqueos se iluminaban en el solemne momento de las charlas sobre la $L u z$ y las Tinieblas. Esta experiencia religiosa básica para un maniqueo correspondía a la identificación de una parte de sí con un alma buena, la que estaría aprisionada en un cuerpo malo; sensación que daría cuenta de cierto dualismo del ser, tomando sentido en el tratamiento al cuerpo que hemos esbozado. En consecuencia, para los maniqueos hay una parte del sí mismo que no pertenece a la pureza, entre las que encontramos lo referido a las pasiones, la cólera, la sensualidad; en definitiva, el cuerpo corrompido. Por consiguiente, las prácticas que hemos presentado, tanto el «sello del seno») como el « rechazo a la Materia. En el primer caso, se refiere a la abstención de toda relación sexual, evitando tajantemente la procreación; y el segundo sello, hace referencia al vegetarianismo estricto y los períodos de ayunos, entre otros aspectos (Bermejo, 2008: 156).

En otros términos, estaban seguros de que el mal no provenía del Dios bueno “(...) creían que provenía de una invasión contra lo bueno, el «reino de la luz», por parte de una fuerza hostil del mal, de igual poder, eterna y totalmente opuesta, el «reino de las tinieblas»." (Brown, 1969: 57) Evidentemente, el dualismo entre alma-buena y cuerpo-malo, exhibido en una lucha entre una fuerza del mal tan fuerte -o más, pensarían algunos- como la del bien, irritó a los cristianos. A pesar de que no son simétricos, lo que se evidencia en la escatología maniquea, debido a que el bien siempre ganaría, como también sería el único en denominarse como Dios. En este sentido,

"si bien el desequilibrio es perceptible en la escatología (que contempla la victoria final del Bien), lo es ya en el hecho de que sólo el principio bueno es llamado «dios», mientras que al principio del Mal nunca se le otorga la denominación de «(dios» -ni siquiera de «dios malo»- ni recibe el menor culto, sino que es calificado en todo caso como «(demonio»." (Bermejo, 2008: 83)

Por consiguiente, se refutaría el posicionamiento de Hegemonio en los Acta Archelai 7 cuando dice “(...) Mani venera a dos dioses (...)” (Dussel, 1974: 124; Bermejo y Montserrat, 2008: 440), ya que como bien hemos expuesto es un Dios, y sólo le correspondería al Reino de Luz dicha denominación. No obstante, en lo que sí podríamos concordar con el autor cristiano es que ambas substancias $^{13}$-y no dioses, como continúa llamándolas- existen eternamente por sí mismas, siendo adversarias mutuamente, y "(...) que el alma que hay en los hombres es una parte de la Luz; que el cuerpo, por el contrario y todo lo que ha sido creado a partir de la Materia es una parte de la Tiniebla." (Bermejo y Montserrat, 2008: 440) La importancia de estos fragmentos es que fueron los primeros escritos de refutación cristiana que, luego utilizará también Cirilo de Jerusalén, por lo que podríamos deducir que Agustín también tuvo siquiera conocimiento de los Acta Archelai.

\footnotetext{
${ }^{13}$ Aun cuando tampoco sean sustancias en términos cristiano-agustinianos, ya que para Agustín toda sustancia es buena, por lo que el mal no podría tener sustancialidad. Y sólo sería una sustancia denigrada.
} 
De este modo, el maniqueísmo sostuvo la co-existencia, desde el principio de los tiempos, de dos sustancias: “(...) la luz (Ormuz) y la oscuridad (Ahriman) $)^{14}$, de donde se deriva que de la primera proviene el bien, equiparándose con Dios; de la segunda, el mal, equiparándose con la Materia." (Rojas, 2016: 99) Ahora bien, como vislumbra Fernando Bermejo no derivan uno del otro como sucede en la creencia cristiano-agustiniana, siendo el mal un derivado y ontológicamente inferior. Más bien, corresponden a fuerzas distintas e igualmente originarias: «ellos [bien y mal] no vinieron de Uno» como nos recuerda un refrán copto - citado más abajo- distanciándose de la propuesta cristiana.

De este modo, Mani predicó que ambas fuerzas tenían orígenes distintos y estaban en el hombre, siendo su espíritu el vínculo a Dios mientras que la materia estaba ligada a la oscuridad. En definitiva, el dualismo maniqueo merece el nombre de absoluto y radical ${ }^{15}$, ya que "ninguno de estos principios es, por tanto, anterior al otro o derivado del otro, y las fuentes maniqueas conservadas -sean occidentales u orientales- no conocen especulaciones ulteriores acerca de su respectivo origen." (Bermejo, 2008: 80)

Bajo estos parámetros, cabe enfatizar el rechazo maniqueo al Antiguo Testamento, principalmente, por la función castigadora que cumplía Dios: “(...) un padre que podía ser al mismo tiempo un manantial de tierna generosidad y de castigo, venganza y dolor." (Brown, 1969: 60) Por lo presentado, el dualismo no fue la única razón para la persecución, aunque sí lo que desencadenaría los otros argumentos como docetismo cristológico, rechazo del Antiguo Testamento, afirmar cierta mutabilidad de Dios, dar culto a Cristo mediante el sol y la luna, proclamar a Mani como Espíritu Santo y la divulgación de una cosmogonía que -para los cristianos- es una fábula (Bermejo, 2008).

En este sentido, las refutaciones de Agustín, otrora un oyente, fue uno de los fundamentos claves de la persecución al maniqueísmo durante el Pontificado de León I (440-461) (Villegas, 2004). Sin embargo, habría que reconsiderar el ataque agustiniano al dualismo maniqueo; en gran medida, debido a que no distaría tanto de sus propias posiciones cristianas. En muchos casos, una gama de aspectos que son atacados gracias a las nuevas conceptualizaciones agustinianas, para perseguir la inmoralidad y perversión maniquea (Rojas, 2016; Viale, 2012). Ahora bien, como revisamos los ataques no tenían asidero efectivo en las prácticas maniqueas, ya que no habría sustento suficiente para las descalificaciones que sufrieron. No obstante, los maniqueos llegaron a ser calificados como infiltrados que buscaban contaminar a la (verdadera) Iglesia (Brown, 1969).

Asimismo, habría sido la necesidad de resguardar cierta perfección dentro de sí lo que llamó la atención de Agustín (Brown, 1969). De esta manera, durante su formación, habría defendido la división del ser entre el bien y el $\mathrm{mal}^{16}$, lo que no pudo seguir aceptando, debido a que "el precio

\footnotetext{
${ }^{14}$ Ambas, tanto Ormuz como Ahriman son traducciones del texto, ya que también las podemos encontrar como Ohrmizd y Ahremen, respectivamente (Bermejo y Montserrat, 2008: 284).

${ }^{15}$ Cabe problematizar si esta radicalidad del dualismo maniqueo tiene -o no- continuidad en el cristianismo agustiniano, lo que estamos investigando en otro artículo. Para ello, recomiendo el texto de E. Dussel (1974).

${ }^{16}$ Lo que habría cambiado tras su conversión al cristianismo en algunos aspectos, en tanto que hay elementos que mantendría.
} 
que parecía habían pagado los maniqueos por el repudio total del mal era haber convertido el bien en algo sumamente pasivo e ineficaz" (Brown, 1969: 63), dejando a Dios en una condición de igual (o similar) potencia a las fuerzas malignas. Como bien expone el fragmento de un Kephalaion copto refiriéndose a los dos principios: "Bendito el que comprende que ellos no surgieron uno de otro, ni que vinieron el uno del otros. ¡Ellos no vinieron de uno!” (Bermejo, 2008: 80)

Entonces, evidentemente, esta coeternidad de los principios produjo que Agustín se retractara de su participación en dicha comunidad. No podía seguir aceptando la doctrina del dualismo maniqueo, debido a los graves efectos que tendría sobre Dios. En gran medida, porque al entremezclarse Bien y Mal, sería el Bien lo que estaría condenado a ser pasivo, dado que serían los miembros del Reino de las Tinieblas que atacan al Reino de la Luz, y éste únicamente se defienda a posteriori. En otras palabras, algunas fuentes señalan la ignorancia luminosa de la oscuridad. O bien, “(...) según otras fuentes, en cambio, la Luz sí parece saber de la existencia de la Tiniebla, pero se mantiene al margen de ella: la Luz es autosuficiente y no desea extenderse hacia las regiones de la Tiniebla, por ejemplo para atraerla hacia sí e iluminarla." (Bermejo, 2008: 93)

Ahora, ya sea que la Luz supiese - o no- de la existencia de la Tiniebla, aquélla no estaría interesada de apropiarse de los territorios de ésta. Por lo tanto, sería esta última, la que azarosamente comenzaría la guerra. En suma, debido a su mero movimiento desordenado se habría enfrentado a la Luz, por lo que ésta tuvo que hacer frente, es decir, tuvo que luchar (Bermejo, 2008: 160-161), a pesar de tensionar el principio de no-violencia que el maniqueísmo defiende. Así, en relación a la lucha que enfrentaría el Bien y el Mal, en el maniqueísmo existe una importante discusión, ya que uno de los preceptos de la religión maniquea es la no-violencia, por lo que sería un punto de tensión dentro del propio sistema de creencias el hecho que Dios tenga que enfrentarse a las Tinieblas.

Siguiendo al propio Fausto, que Agustín tomará como punto central de sus ataques, «nunca, en nuestras afirmaciones, se oyó el nombre de dos dioses〉 (Bermejo, 2008: 83). Consecuentemente, cabe resaltar que el maniqueísmo propugna fervientemente la victoria del Bien sobre el Mal, por lo que aun cuando este dualismo sea radical, las potencias de la Luz y las Tinieblas no son simétricas, sino más bien que habría un importante desequilibro (Bermejo, 2008). En definitiva, a pesar de la victoria de la Luz frente a las Tinieblas, siempre el Bien tiende a perder una parte de sí, nunca logrando recuperar a toda la oscuridad. Sin embargo, la salvación, es decir, la victoria de la Luz, es inminente: "Y cuando encadenen (a Ahremen) en las olvidadas mazmorras y se enseñoreen incluso de él, se hallarán felices, satisfechos y gozosos, puesto que (entonces) no habrá ya nadie que pueda perjudicarles." (Bermejo y Montserrat: 284)

\section{Bibliografía citada}

Agustín, san. (2005) Confesiones. Trad. Silvia Magnavacca. Bs. Aires: Losada. 
Bermejo Rubio, Fernando. (2008) El Maniqueísmo. Estudio introductorio. Madrid: Ed. Trotta.

Bermejo Rubio, Fernando y Montserrat Torrents, José (eds.) (2008) El Maniqueísmo. Textos y fuentes. Madrid: Ed. Trotta.

Capanaga, Victorino. (1977) Introducción. En Agustín, La Ciudad de Dios, Trad. Santamarta, Santos y Fuertes, Miguel. Tercera edición (bilingüe). Madrid: Biblioteca de Autores Cristianos.

Celso. (1989) El Discurso verdadero contra los cristianos. Madrid: Ed. Alianza.

Chapsal, Mauricio. (2018) Prólogo. En Pinto, Daniela. Amor y Política en Agustín de Hipona. Santiago: RIL Editores.

Claro, Andrés. (2009) La Inquisición y la Cábala. Un capítulo de la diferencia entre ontología y exilio. Santiago: LOM Ediciones.

Dal Maschio, E. (2015) San Agustín. El Doctor de la Gracia contra el Mal. España: Batiscafo.

Dussel, Enrique. (1974) El dualismo en la antropología de la cristiandad. Bs. Aires: Ed. Guadalupe.

Escribano, María Victoria (1990) Studia Historica. Historia Antigua, 29-47. Recuperado de: http://revistas.usal.es/index.php/0213-2052/article/view/6312/6325

Gulácsi, Zsuzsanna. (2016) Mani's Pictures: The didactic images of the Manicheans from Sasanian Mesopotamia to Uyugur Central Asia and Tang-Ming China. Leiden-Boston: Brill. pp. 435-455.

Marrou, Henrí. (1960) San Agustín y el agustinismo. Madrid: Aguilar.

Rojas, Cristian. (2016) DIKAIOSYNE: revista semestral de filosofía práctica (31), 95-108. Recuperado de: http://www.saber.ula.ve/bitstream/handle/123456789/42876/articulo5.pdf?sequence=1\&isA llowed $=\mathrm{y}$.

Stoddart, William. (2002) El sufismo. Doctrinas y métodos de la mística del Islam. Trad. Esteve Serra. School of Oriental Studies, University of Durham.

Viale, Adrían. (2012) Byzantio Nea Hellás 31, 147-148. DOI: 10.4067/S0718-84712012000100008

Villegas, R. (2004) Polis. Revista de ideas y formas políticas de la Antigüedad Clásica (16), 213244. Recuperado de: https://dialnet.unirioja.es/servlet/articulo?codigo=1961254 